\title{
INFLUENCE OF PRESSURE AND TEMPERATURE ON COMPACTED PLASTIC-CONCRETE BENDING STRENGTH
}

\author{
The University of Tokyo Student Member ORen Wei \\ The University of Tokyo Regular Member Yuya Sakai
}

\begin{abstract}
Demolished concrete and plastic waste are two increasingly aggravating problems. In this study, a novel method was proposed to simultaneously recycle concrete and plastic wastes by compacting concrete and plastic powders together under pressure and temperature. The influence of compression pressure and temperature as well as the mixture proportion on the bending strength of specimens was investigated. The results showed that pressure and temperature had a positive effect on the specimen strength; however, the molding temperature should not exceed the melting temperature of plastic. The proportion of plastic had a minimal effect on the bending strength of the specimen when plastic accounted for $25 \%$ $75 \%$ of the overall mass of the test piece.
\end{abstract}

\section{INTRODUCTION}

Since the invention of plastic, its production has considerably increased. In fact, by 2018, up to 359 million tons of plastic have been produced worldwide. In 2017, the Environmental Protection Agency report shows that only 8.3\% of the total plastic wastes produced in the U.S. have been recovered and used for incineration or recycling. Most plastic wastes are discarded in landfills, which not only occupies land resources but also causes environmental pollution. It has therefore become urgent to determine new approaches to recycle plastics. Meanwhile, increasing amounts of demolished concrete have also become an increasingly severe problem that confronts society. In Japan, it has been estimated that approximately 35 million tons of concrete wastes are generated annually. Although most of these wastes are used as road subbases, the demand for demolished concrete as road bases, however, has steadily decreased every year. A certain quantity of waste concrete is used as recycled aggregate in new concrete; however, the high quality standards for recycled aggregates that have to be satisfied restrict the application of this method to some extent. A new method for recycling concrete waste through compaction was proposed by Sakai et al. (2016). In their experiment, demolished concrete is crushed and milled into concrete powder and finally compacted under high pressure. This method, however, requires extremely high pressures to generate bond among the fine concrete particles. In this regard, the use of another waste for bonding may reduce the required pressure. In this study, concrete and plastic were heat-compacted together with the aim of simultaneously recycling plastic and construction wastes. Through an experiment, the combined effects of compression pressure and temperature as well as the mixture proportion of these recycled materials were investigated.

\section{EXPERIMENT}

The concrete powder mixed in concrete with a water-cement ratio of 0.4 and plastic (polyethylene) powder were utilized in the experiment. The concrete powder particle size was controlled within $300 \mu \mathrm{m}$ by using a $300-\mu \mathrm{m}$ sieve. The polyethylene plastic (obtained from Japan Feather Field Corporation) used in the experiment had an apparent specific gravity of approximately $0.1 \mathrm{~g} / \mathrm{mL}$. A total of 30 specimens, each with dimensions of $5 \times 45 \times 65 \mathrm{~mm}$, were prepared with different plastic-concrete mass ratios (i.e., $25 \%, 50 \%, 75 \%$, and $100 \%$ ). The thoroughly mixed powder was placed into a square mold and heat-pressed under different pressures (10-50 MPa) and temperatures $\left(65-150{ }^{\circ} \mathrm{C}\right)$. Figure 1 shows the samples fabricated for the experiment; for each condition, three specimens were prepared. Finally, a three-point bending test was performed to evaluate the bending strength.

\section{RESULTS AND DISCUSSION}

Figure 2 shows the bending strength of specimens formed by a 5 -min compression at $100{ }^{\circ} \mathrm{C}$ at different compression pressures. In the graph, the black and red lines indicate the bending strength and density of test pieces, respectively. It can be observed that the bending strength significantly increase with increasing pressure. This is consistent with the increase in test piece density with increasing compression pressure; higher densities indicate lower pore volumes. This compatibility between specimen density and bending strength indicates that higher compression pressures produce specimens with lower pore volumes, resulting in higher bending strengths.

Keywords: Recycling, demolished concrete, plastic waste, hot-pressing

Contact address: 4 Chome-6-1 Komaba, Meguro City, Tokyo 153-8505, Tel: 03-5452-6410 


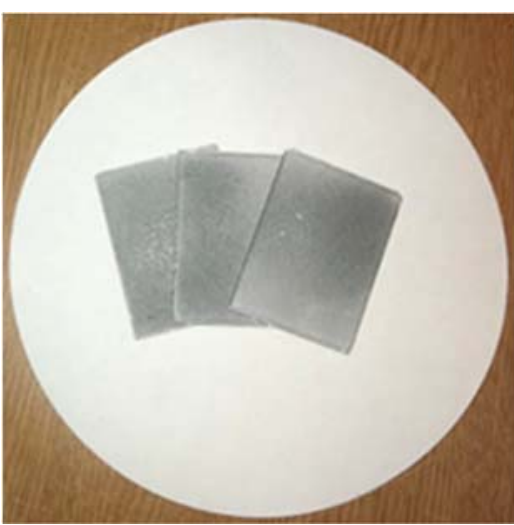

Figure 1. Experimental Samples

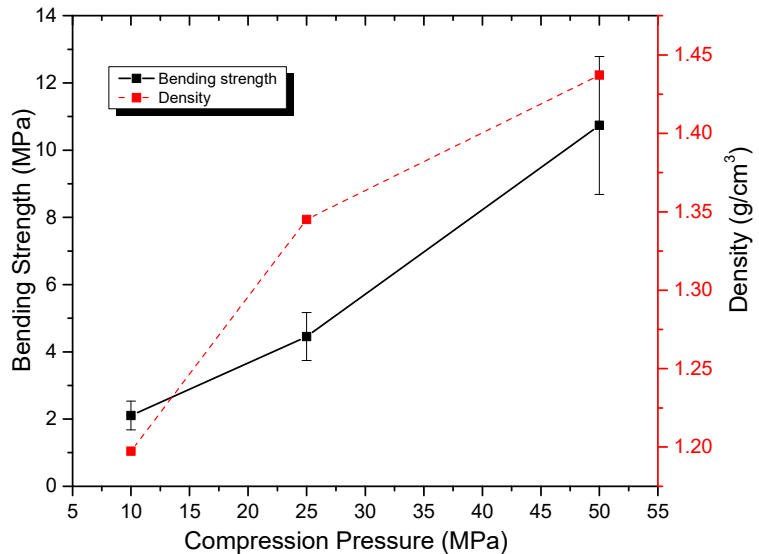

Figure 2. Bending strength under different pressures

The close agreement between density and specimen strength shown by the graphs indicates that compression pressure and porosity are considerably correlated. This suggests that compression pressure has a significant effect on the specimen porosity, that is, when the compression pressure is high, the specimen porosity is low.

Figure 3 shows the bending strength of specimens resulting from a 50-MPa compression for $5 \mathrm{~min}$ at different heating temperatures. It can be observed that the bending strength of the test piece first increases and then gradually decreases with increasing temperature. The point of inflection approximately occurs at the melting point $\left(100-130^{\circ} \mathrm{C}\right)$ of polyethylene. The foregoing indicates that as the heating temperature increases but before reaching the plastic melting point, the plastic particles partially fill the pores because of heat deformation, thereby producing a certain tensile strength. When the heating temperature exceeds the melting point, the plastic may melt into finer particles and fill the pores more easily; however, the plastic may lose its original strength, or the excessively high temperature may cause plastic aging, resulting in strength reduction. The mechanism involved should thus be investigated further in future studies.

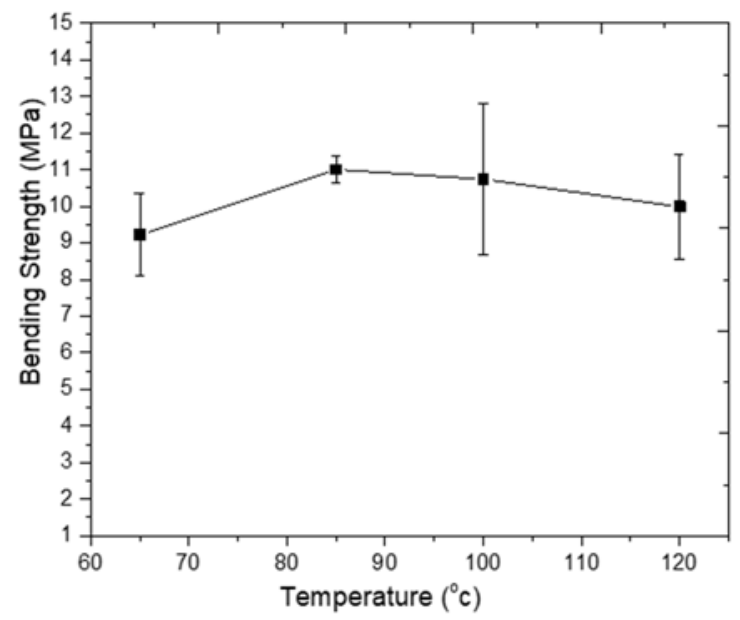

Figure 3. Bending strength at different temperatures

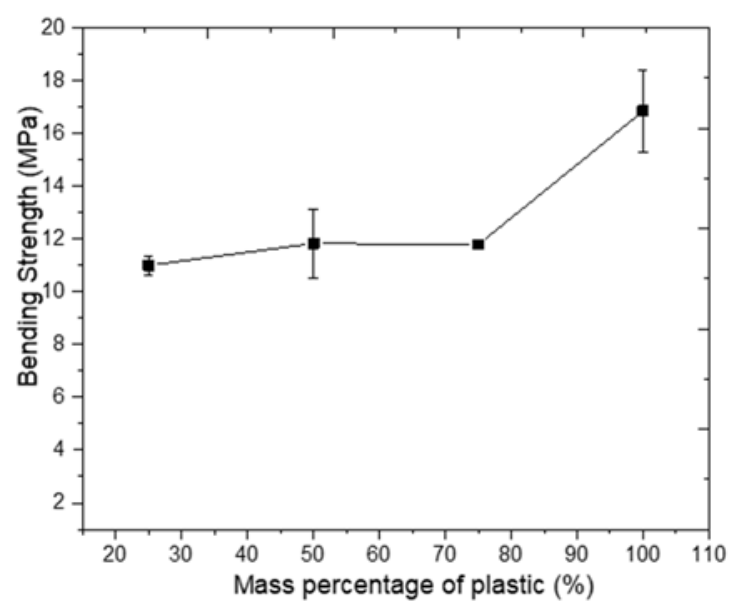

Figure 4. Bending strength at different mix proportions

Figure 4 shows the bending strength of specimens resulting from a 5-min compression at $85{ }^{\circ} \mathrm{C}$ with different plasticconcrete mass ratios. The bending strengths of specimens are practically the same when the plastic to concrete mass ratio is between $25 \%$ and $75 \%$; although there might be a slight increase in strength when the ratio is the latter, the difference is not large. The specific reason for the foregoing requires further investigation. It should be noted that the bending strength of the specimen containing the mixture of the two materials is lower than that of the pure plastic test piece. This indicates that the plastic material has a more considerable contribution to the bending strength of the specimen.

\section{CONCLUSION}

The results obtained in this study showed that recycling concrete with plastic waste by hot pressing is feasible. Within a certain pressure range, the strength of the test piece increases with pressure; however, it should be noted that the temperature of the mold should not exceed the melting temperature of plastic.

\section{REFERENCES}

Yuya Sakai, Biruktawit Taye Tarekegne, and Toshiharu Kishi. 2016. "Recycling of Hardened Cementitious Material by Pressure and Control of Volumetric Change." Journal of Advanced Concrete Technology 14(2): 47-54. 